\title{
A Social Ecological Approach to Exploring Barriers to Accessing Sexual and Reproductive Health Services among Couples Living with HIV in Southern Malawi
}

\author{
Belinda Chimphamba Gombachika, ${ }^{1,2}$ Heidi Fjeld, ${ }^{1}$ Ellen Chirwa, ${ }^{2}$ \\ Johanne Sundby, ${ }^{1}$ Address Malata, ${ }^{3}$ and Alfred Maluwa ${ }^{3}$ \\ ${ }^{1}$ Department of Community Medicine, Institute of Health and Society, University of Oslo, P.O. Box 1130 Blindern, 0318 Oslo, Norway \\ ${ }^{2}$ Faculty of Nursing, Kamuzu College of Nursing, University of Malawi, Blantyre Campus, P.O. Box 415, Blantyre, Malawi \\ ${ }^{3}$ Faculty of Nursing, Kamuzu College of Nursing, University of Malawi, Lilongwe Campus, Private Bag 1, Lilongwe, Malawi
}

Correspondence should be addressed to Belinda Chimphamba Gombachika, belinda.chimphamba@medisin.uio.no

Received 30 September 2012; Accepted 16 October 2012

Academic Editors: H. Balcazar and J. Konde-Lule

Copyright (C 2012 Belinda Chimphamba Gombachika et al. This is an open access article distributed under the Creative Commons Attribution License, which permits unrestricted use, distribution, and reproduction in any medium, provided the original work is properly cited.

\begin{abstract}
With wide access to antiretroviral therapy, people living with HIV are living longer. The reduction in the mother-to-child transmission of HIV has encouraged some people living with HIV to have children and remarry. However, some continue to have limited access to sexual and reproductive health services. The study explores barriers encountered by couples living with HIV in accessing sexual and reproductive health services using the social ecological model. Data were collected using in-depth interviews with twenty couples purposively sampled in matrilineal Chiradzulu and patrilineal Chikhwawa communities in Malawi from July to December 2010. Data were analyzed using framework analysis method. The study findings identify barriers across the five levels of the social ecological model indicating that the use of sexual and reproductive health services is influenced by diverse factors. We suggest three main areas for primary intervention: services must be located closer to their communities and integrated with existing antiretroviral services. In addition, information gatekeepers, both formal and informal, should be empowered with knowledge about sexual and reproductive health, including HIV and AIDS. Finally, there is a need to coordinate the flow of reproductive health, HIV, and AIDS information between Malawi Ministry of Health and formal and informal organizations.
\end{abstract}

\section{Introduction}

HIV remains a challenge to public health in Africa. Recent data indicate that the rate of new HIV infections has decreased; for instance, in 33 countries, HIV incidence has fallen by more than $25 \%$ between 2001 and 2009 [1]. Of these countries, 22 are in Sub-Saharan Africa. However, there are still 22.5 million adults and children living with HIV. Heterosexual contact is the principal mode of transmission seconded by mother-to-child transmission of HIV [1].

With the advent of antiretroviral therapy (ART/ARV), worldwide health improvements have occurred over the last decades and the result has been a dramatic reduction in HIV-related morbidity and mortality, and improvements in quality of life [2-5]. HIV infection may now be considered a chronic illness because the ARVs suppress HIV replication thereby increasing CD4 cell count, delaying clinical progression of AIDS and prolonging survival [6]. Similarly, the number of people living with HIV (PLWH) is increasing due to decreased mortality because of ART [1]. Similar situations have been noted in earlier studies in developed countries such as France, Brazil, and the United States of America $[5,7,8]$.

With a broader spectrum of reproductive options available to PLWH, evidence emerging from research conducted in developing countries indicates that ART may encourage PLWH receiving treatment to reconsider their reproductive decisions such as getting married and having children [2, $4,5,9]$. The use of ART is also associated with increased sexual activity in PLWH, as such increasing the likelihood of 
pregnancies [10]. ART has played an important role in decreasing perinatal HIV transmission to less than $2 \%$, thereby reducing the women's concern regarding HIV transmission to their infants $[11,12]$. Studies from Africa suggest that HIV might modify, but not eliminate, broader desires to have children $[2,13,14]$ and ART use may be associated with increased fertility desire among PLWH possibly through increased hopes for the future. These decisions are related to the "Lazarus effect" [15] where PLWH perceive that ARV allows them to live longer, and, have more "normal" social sexual lives, and possibly have healthy, HIV-negative children $[4,9]$. Consequently, worldwide there has been a shift in research, whereby efforts are now integrating reproductive health in the care and management of PLWH $[8,14]$. However, due to these life adjustments, PLWH have faced challenges in their reproductive decisions [16].

1.1. HIV and AIDS and Reproductive Health Issues in Malawi. Malawi is a multiethnic country with a total population of $13,077,160$. HIV is a challenge to the public health in Malawi. At 10.6\%, Malawi has one of the highest national HIV prevalence rates in the world [1]. Heterosexual contact is the principal mode of transmission, while mother-to-child transmission accounts for $25 \%$ of all new HIV infections. People of the reproductive age group, 15-49 years, are one of the fastest growing groups being diagnosed with HIV [17]. The southern region has the highest prevalence, $15 \%$, which is about twice that of the central, $8 \%$, and northern region, 7\%. Among 3,000 couples sampled in the Malawi Demographic Health Survey (MDHS) in 2008, 85\% were HIV negative and $6 \%$ were HIV positive. Nine percent were discordant; that is, one partner is living with HIV and the other is not. Half of the respondents to the MDHS in 2008 were widowed and $24 \%$ of the respondents were either divorced or separated and living with HIV.

The country has an estimated 675 maternal deaths per 100,000 live births, which is one of the highest maternal mortality ratios globally [17]. In order to address issues related to maternal mortality, the Ministry of Health has initiated several programs. Some of them are development of the Road Map for accelerating the reduction of maternal mortality and morbidity, sexual and reproductive health and rights policy and guidelines, Safe Motherhood Initiative in 1997, and establishment of comprehensive and basic emergency obstetric care. Recently though not yet implemented in all health facilities, Malawi adopted the simplified World Health Organization (WHO) protocol for prevention of motherto-child transmission of HIV (PMTCT) recommending that ART be initiated in all pregnant women living with HIV regardless of clinical or immunologic criteria and be continued throughout pregnancy and breastfeeding [18]. Sexual and reproductive health services in Malawi are provided by a range of actors such as governmental, nongovernmental and faith-based organisations, which are supported by donor communities.

By using the social ecological model (SEM) as an analytical lens, this study explores the barriers to accessing sexual and reproductive health services at the individual, interpersonal, organisational, community, and societal levels to accessing sexual and reproductive health services. Knowing that the dynamics of the reproductive process cannot be properly understood as long as researchers continue to base their conclusions on data collected exclusively from women, we found an opportunity to explore how the experiences of a husband and a wife are unified to produce one outcome by focusing on the couple in their sociocultural contexts.

1.2. Social Ecological Model. Since HIV has myriad effects on the reproductive health of both men and women [19], several authors situate reproductive health, HIV, and AIDS in the arena of public health, consequently, recommending application of theories that can provide this scope to analyze the social and cultural issues involved in couples living with HIV (CLWH) reproductive decisions [19-21]. One way is through use of the social ecological Model (SEM).

Our study is based on the SEM, which recognizes the intertwined relationship existing between an individual and their environment. The SEM developed out of the work of a number of prominent researchers: Urie Bronfenbrenner's Ecological Systems Theory (1979), which focused on the relationship between the individual and the environment; Kenneth Mc Leroy's Ecological Model of Health Behaviors (1988), which classified different levels of influence on health behaviour; and Daniel Stokols's Social Ecological Model of Health Promotion $(1992,2003)$, which identified the core assumptions which underpin the SEM. The work of these and other researchers has been used, modified, and evolved into what is referred to as the Social Ecological Model.

The model addresses the complexities and interdependences between socioeconomic, cultural, political, environmental, organisational, psychological, and biological determinants of behaviour [22]. It recognises that whereas individuals are responsible for instituting and maintaining life style changes necessary to reduce risk and improve health, individual behaviour is influenced by factors at different levels [23]. There are a number of versions of the SEM, which use slightly different classification of these levels. For the purpose of the study, we use five levels according to Sallis and Owen, [24]. First level: individual which includes the characteristics that influence behaviour such as knowledge, attitudes, skills, and beliefs. Second level: interpersonal processes, which provide social identity and role definition such as partner, friends, and family. Third level: organizational which includes rules, policies, and formal and informal structures. Fourth level: community with established norms and values, standards and social networks. The fifth level: societal which includes cultural context and national policies on health.

A major strength of the social ecological approach to health in this study is that it was possible to offer strategies of behavioural change and environmental enhancement. Multilevel analyses among individual, interpersonal, organizational, community, societal, and related intervention strategies were also possible as shown by Reifsnider et al. [25]. At the same time, however, SEM reflects certain practical limitations. The incorporation of multilevel analyses proved to be cumbersome and complex. 


\section{Methodology}

A qualitative approach was deemed most appropriate due to the fact that there is very little existing research that has been conducted thus far. In addition, the exploration of the barriers to accessing sexual and reproductive health services involves sensitive, emotive, and personal topics that can be best captured through careful probing using the qualitative in-depth interview (IDI).

2.1. Study Setting. The informants were recruited from antiretroviral therapy clinics involved in the treatment and care of PLWH at two health centres in southern Malawi. The centres were Ngabu Rural Hospital in Chikhwawa and Ndunde Health Centre in Chiradzulu. The two centres offer inpatient and outpatient HIV and AIDS treatment using multidisciplinary teams and serve primarily low-income individuals from diverse backgrounds. Ndunde is located $7 \mathrm{~km}$ from Chiradzulu district's headquarters while Ngabu is $60 \mathrm{~km}$ from Chikhwawa district's headquarters with an average monthly temperature of $28^{\circ} \mathrm{C}$, with a minimum of $15.2^{\circ} \mathrm{C}$ and a maximum of $45.6^{\circ} \mathrm{C}$. The catchment areas of these two study sites face challenges ranging from food insecurity, low accessibility to safe water, low household income levels and poor communication infrastructure coupled with high prevalence of HIV and AIDS. The communities have access to earth roads, though during the rainy season, the conditions of the roads deteriorate and communication becomes a problem [17].

The two health facilities serve two kinship communities, patrilineal and matrilineal. In Chikhwawa, kinship, marriage, and residence are organised according to patrilineal descent, so that the transfer of, traditionally, cattle, but nowadays money (lobola) from the husband to the bride's family leading to the move of the woman from her natal household to her husband's compound after marriage legitimises marriage. In these compounds, men are related by patrilineal descent and the children become members of the father's descent group. This practice places a married woman in a position of dependence on her affinal kin, especially her mother-in-law. On the other hand, in Chiradzulu the pattern is matrilineal descent and uxorilocal residence. Men leave their natal household to live in their wives' compound after marriage [26], hence creating compounds where children are members of the mother's descent group. The man's dependence on his wife's kin for the land and a place of residence provides an element of social control over the inmarrying man and typically implies a source of tension and exploitation [27].

2.2. Data Collection. Informants were recruited upon receipt of permission to conduct the study following ethical approval from the research and ethics committees in Malawi, College of Medicine Research Ethics Committee (COMREC) and, in Norway, Regional Committees for Medical Research Ethics (REK). Twenty CLWH were recruited in the study using purposive sampling. Informants who were HIV-positive (concordant couples), had informed about each other's HIV status as a couple, and were in the reproductive age group of
18 to 49 years [17] were recruited for the study. The sample size of 40 informants (20 couples) was determined based on Kuzel [28], who recommends a sample size of twelve to more data sources when trying to achieve maximum variation.

Data, which was part of a big study looking at reproductive decisions of CLWH in matrilineal and patrilineal communities, was collected from July-December 2010 and three months were spent in each study setting. This immersion and fluency in vernacular language, Chichewa, enabled the researcher to internalize rather than superficially observe patterns of beliefs, fears, expectations, dominant ideas, values and behaviours of the informants [29]. Practical access to the ART clinics was gained through collaboration with the ART clinic coordinators. In both sites, the ART clinic coordinators identified a contact person with whom the present study was discussed thoroughly. Considerable time was spent with the contact person to ensure that thorough comprehension was gained about the focus and the background for carrying out the study, as well as the objectives and methodological approach of the study. The contact person oriented the researcher at the research site for a period of four days. During the orientation period, the researcher was briefed about the ART clinics' objectives, strategies in place to achieve their objectives, and the activities. A pilot study to test the IDI tool was done at Chiradzulu and Chikhwawa district hospitals during the researcher's orientation period to the study sites.

Couples living with HIV were approached while waiting for their monthly checkup at the two study sites. The information about the research was given to the patients of the ART clinic in two phases: first, as part of the general briefing that all clients received in an open area before the checkup begins and secondly, as a private conversation in an undisclosed room with the contact person. CLWH, who indicated willingness to take part in the study, met the researcher who then asked them a few questions to determine eligibility. Those eligible were accorded an appointment for an interview. Informants gave an oral consent, which was tape-recorded. Informants that consented were assured of confidentiality and were informed that they were free to withdraw from the study if they so wished. During the research activity, all the informants were given snacks and transport reimbursements of $\$ 2$ each.

The IDIs were conducted in vernacular language. IDIs were opted for because they allowed room to explore issues deeper and were interactive in nature thereby enabling clarification of issues during the interview. In addition, they allowed further probing and modification of interview guides in the course of the study [30]. An interview guide was employed to ensure coherence in the study approach and to give the interview sessions a general direction concerning topics raised and discussed. The guide comprised a section on demographic characteristics. It also had an outline of topics with open-ended questions covering counselling, availability, and use of sexual and reproductive health services among other areas. The guide was carefully translated from English to Chichewa. The quality of a translation was verified by an independent translator who translated it back into the original language. Original and back-translated documents were then compared for consistency by the interviewer. The 
TABLE 1: Barriers to accessing sexual and reproductive health services.

\begin{tabular}{|c|c|c|c|c|}
\hline Individual level & Intrapersonal level & Organisational level & Community level & Societal level \\
\hline $\begin{array}{l}\text { Skills } \\
\text { (i) Reading } \\
\text { (ii) Writing } \\
\text { Attitudes } \\
\text { (i) Stigma and } \\
\text { discrimination } \\
\text { (ii) Embarrassment } \\
\text { Beliefs } \\
\text { (i) Gender and } \\
\text { cultural beliefs } \\
\text { about reproductive } \\
\text { health } \\
\text { Knowledge } \\
\text { (i) Past negative } \\
\text { experiences }\end{array}$ & $\begin{array}{l}\text { Partner } \\
\text { (i) Attitudes, beliefs, } \\
\text { and knowledge about } \\
\text { sexual and reproductive } \\
\text { health services } \\
\text { Friends } \\
\text { (i) Misinformation } \\
\text { from peers } \\
\text { (ii) Disapproval from } \\
\text { friends } \\
\text { Family } \\
\text { (i) Family structure } \\
\text { (ii) Disapproval from } \\
\text { kin }\end{array}$ & $\begin{array}{l}\text { Rules } \\
\text { (i) Inconvenient } \\
\text { service hours } \\
\quad \text { (ii) Disapproval from } \\
\text { health workers } \\
\text { Structures formal and } \\
\text { informal } \\
\quad \text { (i) Geographical } \\
\text { accessibility } \\
\quad \text { (ii) Inadequate } \\
\text { counselling from health } \\
\text { workers } \\
\quad \text { (iii) Lack of privacy }\end{array}$ & $\begin{array}{l}\text { Established norms and values } \\
\text { (i) Rigid gender roles } \\
\text { (ii) Loss of traditional } \\
\text { support } \\
\text { Standards } \\
\text { (i) Economic hardships } \\
\text { encountered by informants }\end{array}$ & $\begin{array}{l}\text { National policy } \\
\text { (i) National policies } \\
\text { on sexual and } \\
\text { reproductive health, } \\
\text { HIV, and AIDS } \\
\quad \text { (ii) Lack of free } \\
\text { services of some sections } \\
\text { of the sexual and } \\
\text { reproductive health } \\
\text { services } \\
\quad \text { (iii) Conflicting } \\
\text { information from health } \\
\text { institutions and from } \\
\text { media }\end{array}$ \\
\hline
\end{tabular}

couples were interviewed independently from their spouses, but on the same day to enable free expression of feelings and views. The IDIs were carried out within the area of the ART clinic in offices or outside under trees where comfort and confidentiality was guaranteed. The interviews lasted between 50 minutes to 2.5 hours.

2.3. Data Analysis. Since multiple coders were involved, before data analysis was commenced three research experts (including the principal investigator) in qualitative research underwent two days training on data analysis in order to ensure the consistency of coding. Among other issues, a coding manual was developed which consisted of codes, category names, and rules for assigning codes.

The general principles and procedures for qualitative data framework analysis by Pope et al. [31] were followed. These were familiarization: identifying a thematic framework drawing on a priori issues; indexing: applying the thematic framework to all the data in textual form supported by short text descriptors to elaborate the index heading; charting: rearranging the data according to the appropriate part of the thematic framework, mapping and interpretation rereading transcripts, assigning categories, coding and summarizing codes by theme. The analysis allowed the coding process to remain iterative while also drawing on the general structure provided by the SEM. In this study, the interviews were read through several times to obtain a sense of the whole. Then the texts concerning the utilization of sexual and reproductive health services were extracted. The texts were first coded according to the SEM levels: individual, interpersonal, organizational, community and societal used in this study. The text were further coded into subcategories using the predefined codes according to the SEM factors: skills, attitudes, beliefs, knowledge; friends, family, social networks; rules, policies and informal structures; established norms and values, social networks, economic level of the people and cultural context, national and public policies on health and economy. In order to ensure interrater consistency the codes and categories were discussed among the three researchers who initially did the coding independently. Once the codes and categories were agreed upon, the underlying meaning of the different categories of the codes was formulated into a theme. An example of the coding process is given in Table 2. All the data from digitally-recorded IDIs that were transcribed verbatim were typed. NVivo version 9 was used to analyse and organize the data.

\section{Results}

All of the participating 20 couples reported that they were in a monogamous relationship and indicated current use of a modern family planning method. They were living in their wives' or their husbands' natal compounds depending on organizational form. Thirty-three of the informants were local farmers while only seven male informants had formal jobs four and three from the matrilineal and patrilineal societies, respectively. All of the informants were Christians.

The interviews revealed several barriers, which were organized into the five levels of the socioecological model as indicated in Table 1. It has to be noted that some of the barriers were highly interrelated, thus could naturally be located under any of the five levels. The presentation below was nonetheless chosen as the best way to guide the reader through the informants' elicitation.

\subsection{Individual Level}

3.1.1. Skills. Six informants, two women and four (three women and one man) informants from the matrilineal and patrilineal communities, respectively, had no formal education at all. Thirty-four informants had some schooling; twenty-eight, 14 from each community, had completed primary education while the other six had completed secondary school education (Form 4). Illiteracy presented a challenge to use written media as a channel of communicating reproductive health, HIV, and AIDS issues. This is compounded by the limited visibility and quality of information education and communication materials (IEC) in rural and hard-toreach areas where majority of the population live. Despite the fact that English is the official language, most of the 


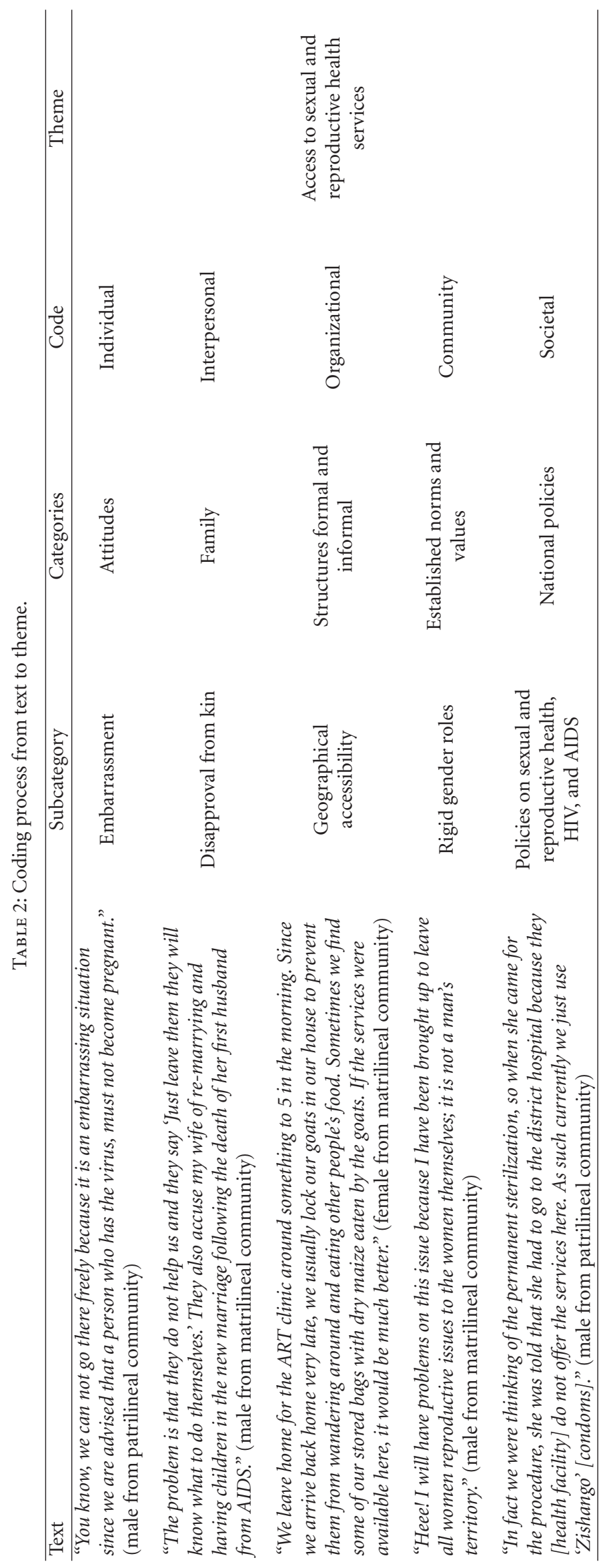


informants who had attended school up to primary level were not able to understand it; therefore, to those who were not able to read, materials printed in English were ineffective. To those who were able to read and write in English, they expressed need for more printed information about sexual and reproductive health services as was the case with HIV and AIDS information.

3.1.2. Attitudes. Experiences of stigma, discrimination, and embarrassment from the society as PLWH were indicated as a barrier to using the sexual and reproductive health services. The informants indicated that the society did not expect them, as PLWH, to be in need of reproductive services because reproduction per se was regarded as a risk factor for HIV infection.

\begin{abstract}
"If at all there were some ridicules they were from here, at the hospital, because the place does not have a fence it is very open as such some of the people we stay with at our village when they see us, they go back home and start informing others that, "They are on medications, they have AIDS."” (male from Patrilineal community)

"You know, we cannot go there freely because it is an embarrassing situation since we are advised that a person who has the virus, must not become pregnant." (male from patrilineal community)
\end{abstract}

3.1.3. Beliefs. Gender and cultural beliefs about reproductive health was expressed by the informants as a barrier to accessing sexual and reproductive health services with some husbands referring the services as "for women only" and their presence as a taboo. One informant expressed how her husband had threatened divorce once he became involved in childbirth issues:

"The time that I was pregnant there was a policy that husbands must access the antenatal clinic with their wives even in the labour ward. However, my husband never did that. He was stubborn and every time I reminded him, he would always shout at me and threatened me saying "The moment I go to those women places [antenatal clinic and labour ward] with you, just know it is the end of our marriage." (female from matrilineal community)

3.1.4. Knowledge. Past negative experiences with use of the sexual and reproductive health services, to some of the informants, deterred future use:

"I can never come here for the services (reproductive health). When I used to come here, I was never comfortable. We could wait outside, had to queue as if we are to receive maize subsidy and we could easily be noticed by passersby that though we are living with HIV we are still indulging in sex or having children, something the community feels we must not do. But at ..., we are respected, we wait in a room and even though we meet people, they just think that we are coming from the general sections of the hospital." (female from matrilineal community)

However, for the women who had been pregnant while living with HIV, they indicated that they had no alternative; they braved these negative attitudes and experiences and accessed the reproductive health service.

\subsection{Interpersonal Level}

3.2.1. Partner. Female informants indicated that at times their husbands' negative attitudes and beliefs, lack of comprehensive reading and writing skills and knowledge about sexual and reproductive health services was a barrier. Their husbands as the head of the family, they indicated, were supposed to be supportive of their access to the available sexual and reproductive health services. One woman from the patrilineal community had this to say:
"I miss out a lot because my husband, just like me, is not able to read English. There was a time when they placed posters at the ART clinic about free services for tubal ligation at Banja La Mtsogolo (Private NGO clinic). We both missed it despite visiting the ART clinic for our monthly consulta- tions." (female from patrilineal community)

3.2.2. Friends. The informants indicated that they shared information with friends who were also living with HIV and kin. The information was sought from them because the informants felt their friends had accumulated wisdom through reflection on their lived experiences. However, informants further narrated that the preferred friends and kin were not able to provide comprehensive information due to both the complexity and their possible lack of upto-date information on reproductive health, HIV, and AIDS issues. It was also during these forums that the informants shared their negative experiences when accessing the sexual and reproductive health services, which, they indicated, they followed.

3.2.3. Family. All the informants were coming from rural, kinship-oriented, and agrarian communities in southern Malawi in the districts of Chiradzulu and Chikhwawa, where family structure was among some of the factors that barred them from accessing sexual and reproductive health services. Lack of family support was more pronounced in couples that had been diagnosed with HIV. These couples usually went against their kin advice-not to marry or remarry and have children in the new marriage relationships. As a result, their kin were not even supportive when it came to help in accessing sexual and reproductive health services.
"The problem is that they do not help us and they say "Just leave them, they will know what to do themselves." They also accuse my wife of re- marrying and having children in the new mar- riage following the death of her first husband from AIDS." (male from matrilineal community) 
Even though kinship can furnish support to PLWH, the decisions of marrying and having children while living with HIV diminished the support. The situation was even worse when family members discourage or suggest alternatives to accessing health care such as visiting traditional healers; spouses were reluctant to seek to sexual and reproductive health services.

\begin{abstract}
"My father in law is a traditional healer while my mother in law is a traditional birth attendant. When I had just married my wife, they never approved their daughter to go to the hospital. Whenever I suggested to them that my wife had to go to the hospital, they all refused, it was like a tag of war. Until when she was so sick with AIDS, it is when they accepted to take her to the hospital. So all along we could not access the services (reproductive health services)." (male from matrilineal community)
\end{abstract}

\subsection{Organizational Level}

3.3.1. Rules. Inconvenient service hours were indicated as a barrier to accessing the sexual and reproductive health services. All the services at the study sites were supposed to be providing sexual and reproductive health services from 8 am to $12 \mathrm{pm}$ Mondays through Fridays. However, due to shortage of staff in these health facilities, the services were provided twice a week. Hence male informants who wished to access the services indicated that the times and days coincided with the times when they have to fend for their families.

Stipulated childbearing messages used by the health workers disapproving CLWH to have children were a deterrent to the services. The majority indicated receiving advice from the health workers against becoming pregnant. Informants also mentioned judgemental tones from the health workers when they could not follow the advice on pregnancy prevention.
"The doctors discourage us. We are told that we must not have children but when we go back home, we just decide to do it as a couple. When we come back pregnant, they shout at us." (female from matrilineal community)

\begin{abstract}
"The health personnel shout at us. They say that they give us condoms to use but surprisingly the women come back pregnant. They further ask us if we are really concerned with our health because anyone with HIV is not supposed to get pregnant." (male from patrilineal community)
\end{abstract}

The time spent with the health workers during consultations at either the ART or maternity clinics was longer during the first visits. During the consecutive visits, counselling hardly took place. The majority of the informants complained about lack of comprehensiveness in the information they received as cited by one male informant.

"Information on reproductive health is given but
it is not adequate, it is as if they skate around these issues, we expect the health workers to tell us everything." (male from matrilineal community)

According to the informants, the form of question was often closed-ended and leading, for instance, "how are you?" and "are you facing any problems?" Informants related this to the health workers' ever-busy schedule due to shortage of staff in attending to the long consultation queues at the ART clinic. Consequently, the informants did not ask any questions to the health workers to avoid "taking up too much of the health workers time" when other patients were on the long queue waiting to be seen by the same health worker.

"They are in a hurry so you cannot even ask them
questions, they just greet us: "How are you this
morning, do you have any problem today?" So if
you have a problem you inform the doctors that
such and such is bothering me and they just pre-
scribe the drugs for you." (female from matrilineal
community)

Few male spouses that had once accessed the sexual and reproductive health services indicated that although there was a government policy that men must be involved in the antenatal health education classes, the fathers who wanted to be involved in the care often felt excluded except for the HIV blood tests that were mandatory. To them, this was a strong indication that the health workers were not ready to handle men in these reproductive health service outlets.

3.3.2. Formal and Informal Structures. Geographical accessibility was expressed as a barrier to accessing sexual and reproductive health services. Even though the informants came from catchment areas surrounding these health facilities, the average time to and from the health facility ranged from one hour to three hours on foot. Most of the villages in these communities have access to unpaved road, and, during the rainy season, the conditions of the roads deteriorate and communication becomes a problem in some of the remote villages. Informants who had managed to access the sexual and reproductive health services narrated their consultation waiting experiences. In all study sites, the problem of long waiting hours was cited as a barrier. The mean time spent at the ART clinic was six hours. Thus they were wondering what would happen if they had to attend several clinics the same day. Some informants explained how they had to spend the whole day away from home just for the ART services.

\footnotetext{
"You can come here very early in the morning, only to be attended to late in the afternoon; I really do not know the reason for the delay in opening the clinic. I would think twice if I also had to attend the sexual and reproductive health services on the same day. While at Nchalo, by 7:30 am, the clinic is in operation, the nurses, doctors are already there working. As such, you go back home and arrive in good time." (male from patrilineal community)
} 
Similar sentiments were echoed by a woman from the matrilineal community:

\begin{abstract}
"We leave home for the ART clinic around something to 5 in the morning. Since we arrive back home very late, we usually lock our goats in our house to prevent them from wandering around and eating other people's food. Sometimes we find some of our stored bags with dry maize eaten by the goats. If the services were available here, it would be much better."
\end{abstract}

Lack of synchrony of the reproductive health and ART services coupled with long travelling and waiting hours was on itself a barrier.

"I walk for two hours from home and Imagine I
had to wait this long just for ART services what
if I had also planned to go to Family planning or
escort my wife to the Antenatal clinic, I think I
would need to spend two days here. As such I just
come for the life saving drugs and off I go the
other issues will be sorted out later." (male from
patrilineal community)

The informants indicated lack of privacy at the time of their consultation with the health workers as a barrier to further accessing the sexual and reproductive health services. They explained that much of the discussions and general assessments (physical assessment) take place in the waiting places. Furthermore, in one health facility where the temperatures can go as high as $42^{\circ} \mathrm{C}$, the door in the consultation room is always open with desks situated near open windows adjacent to the waiting area. In some cases, two health workers would conduct the consultations in the same room. The informants indicated feeling very uncomfortable with these arrangements where they had to disclose their HIV-positive status in the presence of others. One female informant who had a secondary school education indicated that when she once expressed her dissatisfaction she was told that "If you want "foreign care" "zachizunguzo" [privacy], seek consultation at a private clinic."

\subsection{Community Level}

3.4.1. Established Norms and Values and Expected Standards. Rigid gender roles in the communities that the informants came from, were cited as a barrier. They explained that in these traditional settings, the reproductive arena including information giving is mostly controlled by the elderly women (grandmothers, mothers-in-law, and aunts). These women make most of the reproductive decisions, with little or no consultation with men or health workers, except when more serious decisions are contemplated. As a result, the male informants did as per societal expectation. Asked whether they were willing to access the services if the society approves male involvement in these services, male informants from matrilineal and patrilineal communities, respectively, in their separate interviews indicated
"Heee! I will have problems on this issue because I have been brought up to leave all women reproductive issues to the women themselves; it is not a man's territory."

"That will not be possible; women reproductive issues are kept a secret from us."

According to the informants, loss of traditional support for married couples living with HIV especially in the matrilineal community was a barrier to accessing some of the sexual and reproductive health services. This was in cases where the kin were not in support of the couple's marriage and having children as PLWH. They indicated that grandmothers, mothers-in-law, and aunts were in charge of reproductive matters. With their decisions, they explained that the traditional support systems are no longer willing to assist them, for example, when and where to access sexual and reproductive health services.

In the patrilineal community, the experiences were different. Traditional fora for communicating important information were related to marriage formalities: Luphato (when a gift in the form of a "chitenje" (piece of cloth) and money are given to a girl/woman from her boyfriend as a sign of marriage proposal, which she has to show to her parents). Chifunukura mulomo (when money is given to a girl by her boyfriend in order to initiate discussions of marriage proposal), Maonano (when money is given to a girl's parents from the boy's parent to initiate first discussions about marriage issues) and Lobola (bride price). These marriage fora are the most recognised channels for disseminating important messages including issues regarding access to sexual and reproductive health services. However, the informants still expressed dissatisfaction especially that they are different, living with HIV. Their narratives indicated that the information is usually not comprehensive and the elders conclude with the words: "follow the hospital advice diligently."

3.4.2. Standards. Another barrier was the informants' experiences of economic hardships. The informants from both matrilineal and patrilineal communities who were mostly unemployed and relied on their local gardens to produce explained that lack of finances affected their ability to access sexual and reproductive health services. Male informants narrated their lack of being able to fulfil the provider role, as expected in their community mainly due to lack of money. In both communities, it is the husbands' duty to provide for the family. They need money for transport or health services, which in some cases necessitate payment. They all explained that in such a situation they had to choose between daily necessities and the health care. With their low social economic status, ART services were a priority because they felt they were more lifesaving than sexual and reproductive health services, which they felt were mostly preventive.

\subsection{Societal Level}

3.5.1. National Policy. Male informants expressed the view that the national policy concerning the involvement of men 
in sexual and reproductive health services did not take into account the social and cultural expectations they face. They all explained that in such a situation they had to choose between adding more stress to their already stressful life with HIV and visiting the services, which they felt were mostly preventive and were for women. As such, they blamed the national policy for imposing their presence in the women's reproductive health arena without prior thorough assessment of their views.

The informants also blamed the national policy for their health facilities on absence of free services of some family planning methods: Norplant, intrauterine cervical device (IUCD) and tubal ligation. They reported being told that such services were only to be accessed either at central or district hospitals. If anyone was in need of such services, they had to travel outside their community, which to most of them was on average a two-day journey. As such, the informants suggested having those services provided at their current health facilities.

\begin{abstract}
"In fact we were thinking of the permanent sterilization, so when she came for the procedure, she was told that she had to go to the district hospital because they [health facility] do not offer the services here. As such currently we just use "Zishango" [condoms]." (male from patrilineal community)
\end{abstract}

Conflicting information from health institutions and from the media about reproductive health was a barrier to accessing sexual and reproductive health services. They indicated that there is a lot of information on the radio about reproductive health for PLWH. One of such programmes was the "Mungathe" (It is possible). This programme advocates that it is possible for PLWH to have HIV-negative children provided they follow stipulated guidelines. Meanwhile, the sexual and reproductive health services in their respective health facilities are not in favour of such messages.

"By then there was a policy by the government which was aired on the radio that; every woman who was HIV-positive and had a child must breastfeed up to 6 months to prevent transmitting the virus to the child and milk supplements will be provided. So when we got the information, it was a hint to us that maybe the government wants to increase its population thus we were there to help the government. We then went for it." (male from matrilineal community)

"There is an advert that is aired frequently on radio known as "Mungathe." The main message is that although a person has HIV, they can still have a child and those who really want to have a child can go and discuss with nurses at the hospital. As such, these messages act as a driving force for the couples to get pregnant. However, when we visit the nurses they shout at us" (male from matrilineal community)
Informants indicated that in such situations they opted to go by what is in their best interest and shun the sexual and reproductive health services because of the critique.

\section{Discussion}

The findings in this study echo the general existing literature regarding barriers to accessing health services among PLWH [32-34]. Independent of kinship organisation, CLWH experience similar barriers. In this qualitative study, the barriers to accessing sexual and reproductive health services by CLWH were more readily understood by using the socioecological model. The results indicate that primary intervention needed for the CLWH include improving access to the sexual and reproductive health services by bringing the services closer to CLWH communities and synchronizing informants' calendar of ART clinic visit with that of routine sexual and reproductive health services. In addition, it is imperative to empower gatekeepers (formal and informal) with knowledge about sexual and reproductive health services, HIV, and AIDS. Finally, there is need to coordinate the information flow between the main Malawi government health providers and Ministry of Health with other formal and informal organizations about sexual and reproductive health service, HIV, and AIDS information.

4.1. Access to the Sexual and Reproductive Health Services. One reason that was cited as a barrier to accessing sexual and reproductive health services was fear of stigma, discrimination, and embarrassment. Given the potential for horizontal and vertical transmission and the continuing social stigma of HIV illness and mortality, there is still stigma that surrounds HIV and reproductive health issues in the communities where these couples came from. Furthermore, despite the cited significant medical advances and the importance of marriage and childbearing, the society and health care programs continue to recommend that PLWH refrain from marriage and childbearing. Health workers continue stigmatizing CLWH who access sexual and reproductive health services. Similar findings have also been noted by Agadjanian and Hayford, [13], Cooper et al., [35], BeyezaKashesya et al., [36], Newmeyer et al., [15], and Nóbrega et al., [37]. We are aware that if the finding is ignored, it raises biomedical concerns about the risk of HIV super infection, viral recombination, and transmission of drug-resistant virus in cases where unprotected sex is practiced. If no intervention is put in place, Malawi's maternal and infant mortality due to HIV and AIDS will continue to be high. Therefore, we suggest a cultural sensitive health programme embedded in these local realities that accept CLWH to continue to access antenatal, family planning, and PMTCT services without reprisal.

In keeping with other research, we have shown that cost, in terms of time and distance to the health facility, waiting for services and in monetary terms, is a barrier to accessing reproductive health facilities $[32,33]$. We suggest bringing free sexual and reproductive health services closer to their communities through mobile clinics. One way of bringing the services closer is by establishing monthly 
mobile/outreach clinics to communities far away from the health facilities, which is nonexisting in the government health facilities. The few mobile/outreach clinics in health facilities operated by nongovernmental organisations however have their own focuses [38]. The clinics would be offering multiple health services including sexual and reproductive health services regardless of HIV serostatus. The implementation of such a service should be adapted to local circumstances, for example, scheduling the services on market days, malaria and diarrhoea services during rainy season. The multiple health services priorities should also reflect the needs of the communities. In order to promote community accessibility of the services, promote local understanding and ownership, and gain cooperation, we suggest that the health workers meet with village leaders to introduce the services. It is from these meetings that the clinic sites and priority services to be offered, apart from ART and reproductive health, will be chosen. Another possible solution would be to synchronize informants' calendar of ART clinic visit, which usually ranges from one to two months, with that of routine antenatal and family planning services.

To the illiterate and semi-illiterate individuals, media services could be brought closer by making them available in the vernacular language, Chichewa. Radio programmes on reproductive health, HIV, and AIDS should also be in the vernacular language and be broadcast at a suitable time for the target population. This is important because studies have shown that mass media are the most effective means of communication for changing attitudes $[39,40]$.

4.2. Information Empowerment. In the study, publication and distribution of reproductive health service information outside the informants' traditional channels and illiteracy hindered the informants from accessing sexual and reproductive health services. The Malawi demographic health survey conducted in 2008 confirms our results that in Malawi a lot of information that has been published and distributed is not readily accessible to the rural masses owing to high illiteracy rate currently at 32\% for women and 19\% for men [17]. Empowering already existing and accepted structures of information dissemination, PLWH support group peer leaders, village elders/local counsellors, with reproductive health, HIV and AIDS knowledge and skills after a needs assessment, could also provide a favourable solution. Importance of these community health workers has been proved and a success in increasing access and coverage of reproductive health [33, 41-43], HIV, and AIDS services [44]. Empowerment of community health workers should also equip them with the tools to assess what changes need to be done and at what level of the socioecological model. In addition, given the low-literate background of many PLWH support group peer leaders, village elders/local counsellors as well as the difficulties of carrying around large health manuals by literate community health workers, touch-tone telephony interfaces for information access becomes a potentially viable alternative, especially that cell phones are quickly becoming ubiquitous [45]. By making a telephone call to an automated system, and conversing with it in Chichewa, they could gain access to the information they seek. The system would need to be easy to learn, and easy to use, yet should enable access to a potentially vast amount of health information, as quickly and as effectively as possible. Designing, developing, and evaluating such a system are the core goals of the Malawi Ministry of Health.

Existing literature in Malawi confirms our finding that in the traditional setting whether in the matrilineal or patrilineal community men do not access reproductive activities, and the reproductive arena including information giving is mostly controlled by the elderly women (grandmothers, mothers-in-law, and aunts). These women make most of the reproductive decisions, with little or no consultation with men or health workers, except when more serious decisions are contemplated [46, 47]. The informants indicated that cultural norms play a role in determining where and when to accesse sexual and reproductive health services. Empowering these already existing and accepted structures with knowledge about the importance of male involvement in sexual and reproductive health services could be a step ahead in promoting access of men to sexual and reproductive health services.

Misinformation from PLWH and kin acted as barriers to accessing reproductive health care services by CLWH. An example of a study that concurs with the findings is by Veinot et al. [48], suggesting that PLWH and kin must get extra information from these services to prevent similar situations arising when they misinterpret meaning of biomedical issues or overgeneralize situations as they interpret personal stories.

4.3. Information Flow. In Malawi, the guidelines/policy for care of PLWH by the HIV and AIDS and reproductive health units recommend offering all men and women conception counselling and care as a component of their routine care. The purpose of the care is to improve the health of every woman before conception by providing education and counselling targeted to the individuals' needs, and identifying risk factors for adverse maternal or foetal outcomes [49]. However, the study has shown that health workers promote the idea that PLWH should not have children. This is based on the official government HIV-testing and counselling (HTC) training manual that indicates avoiding pregnancy as one of the ways to "live positively" [50] and that "if HIVpositive couples strongly feel that they want a child, provide and offer the following counselling..." [49]. This clearly highlights the conflicting messages targeting the same population. It is therefore not surprising that conflicting messages emanate either from the health institutions or media. Once these conflicting messages further clash with CLWH reproductive health decisions, access to sexual and reproductive health services is avoided. In order to address the situation, we suggest that before any information pertaining to reproductive health, HIV, and AIDS is produced, it must be thoroughly scrutinized and compared with existing information. Such a responsibility should be coordinated by the main Malawi government health providers, Ministry of Health.

Male informants from both study sites indicated that the men who wanted to be involved in care at the maternity clinics often felt excluded. This is very discouraging especially when Malawi is advocating for male involvement in sexual 
and reproductive health services [51]. The health workers must be educated so that they can change their beliefs that maternity clinics are only for women in order to make the men equal partners of the programmes. The observed behaviour may be due to lack of guidelines for the health workers on how to handle men in hospital maternity sections [52] or use of guidelines which are "silent" or nonprescriptive on sexual and reproductive health services and men. Another possible reason could be due to the presence of powerful social norms and stereotyping attitudes, regarding male involvement in sexual and reproductive health services, in the communities. Health workers' dual loyalty pressures (professional and community member), attitudes and values, could be a possible explanation. These findings are similar to previous studies conducted among PLWH and with both PLWH and health workers by Harries et al., [53], Nóbrega et al., [37], and Orner et al. [54]. Cultural differences between a provider and a patient can pose serious challenges to effective communication, especially if one holds negative attitude towards the other's cultural beliefs or if the two differ in their communicative preferences and expectations for the consultation [55]. In contrast, in Vietnam where there are more social pressure to continue family lineage, health workers are more supportive of the reproductive decisions made by PLWH [55]. Therefore, there is a pressing need for development of prescriptive guidelines for the men. However, effective prescriptive guidelines can only be developed by first understanding the men so that the right information is sought from them through research. With available written procedures, there is an increased probability that health workers would know how to deal with men who access sexual and reproductive health services [56].

Being understaffed and concerns about time constraints by health workers were some of the reasons that the informants narrated as barriers to accessing sexual and reproductive health services timely. These are not new problems, as they have been indicated by other authors in their previous studies who concluded that being understaffed is a challenge, but it does not justify the lack of provision of services $[57,58]$. Of late, changes in the health care system have put more responsibility on patients to be active participants in decision making, self-care, and disease management. Active participation presumes the person will have the necessary information and health services [59]. Therefore, there is need for the employers to assess and revisit the current staffing in the clinics that provide sexual and reproductive health services, for instance task shifting, has been employed in some settings in Sub-Saharan Africa as a coping mechanism for general and specific human resource shortages [44].

Appreciating the complexities of adopting the identified three main areas for primary intervention for the CLWH: access, information empowerment, and coordination, we suggest that the interventions be rolled out as a pilot project in one rural community. Data from the projects' evaluation would later be pooled to form a database of best practices that can be shared widely. This database can also be a starting point for other programmes and organisations dealing with PLWH to follow as they either initiate or modify their reproductive health, HIV, and AIDS services.
4.4. Methodological Considerations. Both the findings and limitations in this study raise a number of issues concerning reproductive health and couples living with HIV which merit further attention to the research agenda. First, we did not conduct interviews with health workers. Such information could have strengthened the findings of this study and allowed us to present a more nuanced view of health worker perspectives about PLWH and access to sexual and reproductive health services. Future studies should combine both informants and health workers interviews with direct observations of the routine consultations or care after thorough considerations on the ethical issues. Secondly, due to the nature of the study design, the results are limited to concordant couples living with HIV from the two study settings, hence cannot be generalised beyond these two study sites.

\section{Conclusion}

The results demonstrate that couples, independent of kinship organisation, face barriers to accessing sexual and reproductive health services across the five levels specified in the social ecological model: individual, interpersonal, organizational, community, and societal. By incorporating these levels in a qualitative study, the barriers to accessing sexual and reproductive health services by CLWH were more readily understood. Furthermore, recommendations that take into account the interdependence of these levels informing the choice of intervention to improve access to sexual and reproductive health services in Malawi are generated. This approach also highlights the need to differentiate between changing barriers at the individual and interpersonal levels and the consequences of making these changes that will require a different approach from the higher-level components. The fact that some of the barriers were highly interrelated, thus could be located under any of the five levels, does not affect the quality of the results. We therefore suggest three main areas for primary intervention for the CLWH: firstly, improving access to the sexual and reproductive health services by bringing the services closer to CLWH communities and integrating them with ART services. secondly, empowering information gatekeeper (formal and informal) with knowledge about sexual and reproductive health services, HIV, and AIDS. However, task shifting as a potential solution to help address the limited access to sexual and reproductive health, HIV, and AIDS services requires further study to ensure effective implementation. Finally, coordinating the information flow between the main Malawi government health providers and Ministry of Health with other formal and informal organizations about sexual and reproductive health service, HIV, and AIDS information.

\section{Conflict of Interests}

The authors declare that they have no conflict of interests.

\section{Acknowledgments}

The authors express their gratitude to the couples living with HIV who shared their views and experiences. It is the 
authors' hope that their contributions will someday bring change to their lives. The authors also thank the University of Oslo, Department of Health and Society Section for Community Medicine, and University of Malawi, Kamuzu College of Nursing, for the NUFU Sponsorship and for their support.

\section{References}

[1] "Joint United Nations Programme on HIV/AIDS (UNAIDS)," Global Report: Report on the Global AIDS Epidemic, Geneva, Switzerland, 2010.

[2] D. Cooper, J. Harries, L. Myer, P. Orner, H. Bracken, and V. Zweigenthal, "Life is still going on: reproductive intentions among HIV-positive women and men in South Africa," Social Science and Medicine, vol. 65, no. 2, pp. 274-283, 2007.

[3] R. Isingo, B. Zaba, M. Marston et al., "Survival after HIV infection in the pre-antiretroviral therapy era in a rural Tanzanian cohort," AIDS, vol. 21, supplement 6, pp. S5-S13, 2007.

[4] T. Kredo, J. S. Van der Walt, N. Siegfried, and K. Cohen, "Therapeutic drug monitoring of antiretrovirals for people with HIV," Cochrane Database Systematic Review, vol. 8, no. 3, p. CD007268, 2009.

[5] V. Paiva, N. Santos, I. França-Junior, E. Filipe, J. R. Ayres, and A. Segurado, "Desire to have children: gender and reproductive rights of men and women living with HIV: a challenge to health care in Brazil," AIDS Patient Care and STDs, vol. 21, no. 4, pp. 268-277, 2007.

[6] J. E. Gallant, "Strategies for long-term success in the treatment of HIV infection," Journal of the American Medical Association, vol. 283, no. 10, pp. 1329-1334, 2000.

[7] S. Attia, M. Egger, M. Müller, M. Zwahlen, and N. Low, "Sexual transmission of HIV according to viral load and antiretroviral therapy: systematic review and meta-analysis," AIDS, vol. 23, no. 11, pp. 1397-1404, 2009.

[8] I. Heard, R. Sitta, F. Lert et al., "Reproductive choice in men and women living with HIV: evidence from a large representative sample of outpatients attending French hospitals (ANRSEN12-VESPA study)," AIDS, vol. 21, no. 1, pp. S77-S82, 2007.

[9] L. T. Matthews and J. S. Mukherjee, "Strategies for harm reduction among HIV-affected couples who want to conceive," AIDS and Behavior, vol. 13, no. 1, pp. S5-S11, 2009.

[10] K. Peltzer, L. W. Chao, and P. Dana, "Family planning among HIV positive and negative prevention of mother to child transmission (PMTCT) clients in a resource poor setting in South Africa," AIDS and Behavior, vol. 13, no. 5, pp. 973-979, 2009.

[11] C. S. Chasela, M. G. Hudgens, D. J. Jamieson et al., "Maternal or infant antiretroviral drugs to reduce HIV-1 transmission," The New England Journal of Medicine, vol. 362, no. 24, pp. 2271-2281, 2010.

[12] S. Kanniappan, M. J. Jeyapaul, and S. Kalyanwala, "Desire for motherhood: Exploring HIV-positive women's desires, intentions and decision-making in attaining motherhood," AIDS Care, vol. 20, no. 6, pp. 625-630, 2008.

[13] V. Agadjanian and S. R. Hayford, "PMTCT, HAART, and childbearing in Mozambique: an institutional perspective," AIDS and Behavior, vol. 13, supplement 1, pp. S103-S112, 2009.

[14] I. F. Hoffman, F. E. A. Martinson, K. A. Powers et al., "The year-long effect of HIV-positive test results on pregnancy intentions, contraceptive use, and pregnancy incidence among Malawian women," Journal of Acquired Immune Deficiency Syndromes, vol. 47, no. 4, pp. 477-483, 2008.
[15] T. Newmeyer, S. Tecimer, D. Jaworsky, S. Chihrin, K. Gough, A. Rachlis et al., "Case series of fertility treatment in HIVdiscordant couples (male positive, female negative): the Ontario Experience," PLoS ONE, vol. 6, no. 9, Article ID e24853, 2011.

[16] S. Russell and J. Seeley, "The transition to living with HIV as a chronic condition in rural Uganda: working to create order and control when on antiretroviral therapy," Social Science and Medicine, vol. 70, no. 3, pp. 375-382, 2010.

[17] National Statistical Office, "Malawi demographic and health survey 2010,” Tech. Rep., Zomba, Malawi, 2010.

[18] World Health Organization, Antiretroviral Drugs for Treating Pregnant Women and Preventing HIV-Infection in Infants. Recommendations for a Public Health Approach, Geneva, Switzerland, 2010.

[19] M. Berer, "HIV/AIDS, sexual and reproductive health: intimately related," Reproductive Health Matters, vol. 11, no. 22, pp. 6-11, 2003.

[20] S. Gruskin, L. Ferguson, and J. O’Malley, “Ensuring sexual and reproductive health for people living with HIV: an overview of key human rights, policy and health systems issues," Reproductive Health Matters, vol. 15, supplement 29, pp. 4-26, 2007.

[21] M. Collumbien, J. Busza, J. Cleland, and O. Campbell, Social Science Methods for Research on Sexual and Reproductive Health, WHO, Geneva, Switzerland, 2012.

[22] D. Stokols, "Translating social ecological theory into guidelines for community health promotion," American Journal of Health Promotion, vol. 10, no. 4, pp. 282-298, 1996.

[23] J. P. Elder, L. Lytle, J. F. Sallis et al., "A description of the socialecological framework used in the trial of activity for adolescent girls (TAAG)," Health Education Research, vol. 22, no. 2, pp. 155-165, 2007.

[24] J. Sallis and N. Owen, "Ecological models of health behaviour," in Health Behaviour and Health Education: Theory, Research and Practice, K. Glanz, B. Rimer, and F. Lewis, Eds., pp. 462484, San Francisco, Calif, USA, 3rd edition, 2002.

[25] E. Reifsnider, M. Gallagher, and B. Forgione, "Using ecological models in research on health disparities," Journal of Professional Nursing, vol. 21, no. 4, pp. 216-222, 2005.

[26] A. M. Chimbiri, “The condom is an 'intruder' in marriage: evidence from rural Malawi," Social Science and Medicine, vol. 64, no. 5, pp. 1102-1115, 2007.

[27] P. E. Peters, "Against the odds. Matriliny, land and gender in the shire highlands of Malawi," Critique of Anthropology, vol. 17, no. 2, pp. 189-210, 1997.

[28] A. Kuzel, "Sampling in qualitative inquiry," in Doing Qualitative Research, B. Crabtree and W. Miller, Eds., pp. 31-44, Sage, Newbury Park, Calif, USA, 1992.

[29] R. Emerson, R. Fretz, and L. Shaw, Writing Ethnographic Fieldnotes, chapter 5, The University of Chicago, London, UK, 1995.

[30] J. Morse and L. Richards, Readme First for a User's Guide to Qualitative Methods, Sage, London, UK, 2nd edition, 2007.

[31] C. Pope, S. Ziebland, and N. Mays, "Analysing qualitative data," British Medical Journal, vol. 320, no. 7227, pp. 114-116, 2000.

[32] T. Delvaux and C. Nöstlinger, "Reproductive choice for women and men living with HIV: contraception, abortion and fertility," Reproductive Health Matters, vol. 15, no. 29, pp. 4666, 2007.

[33] S. Merkel, J. Otai, L. Archer, and P. Lynam, "Making comprehensive care for HIV a reality in African Urban Slums.," Baltimore, Jhpiego, http://www.jhpiego.org/files/UrbanSlums_ Comprehensive_Care.pdf, 2008. 
[34] R. Fabienne, D. Hercot, C. Quédraogo, T. Delvaux, S. Samaké, J. van Olmen et al., "Sub-Saharan Africa and the health MDGs: the need to move beyond the "quick impact" model," Reproductive Health Matters, vol. 19, no. 38, pp. 42-55, 2011.

[35] D. Cooper, J. Moodley, V. Zweigenthal, L. G. Bekker, I. Shah, and L. Myer, "Fertility intentions and reproductive health care needs of people living with HIV in Cape Town, South Africa: implications for integrating reproductive health and HIV Care services," AIDS and Behavior, vol. 13, no. 1, pp. S38-S46, 2009.

[36] J. Beyeza-Kashesya, F. Kaharuza, F. Mirembe, S. Neema, A. M. Ekstrom, and A. Kulane, "The dilemma of safe sex and having children: challenges facing HIV sero-discordant couples in Uganda," African Health Sciences, vol. 9, no. 1, pp. 2-12, 2009.

[37] A. A. Nóbrega, F. A. S. Oliveira, M. T. G. Galvão et al., "Desire for a child among women living with HIV/AIDS in northeast Brazil," AIDS Patient Care and STDs, vol. 21, no. 4, pp. 261267, 2007.

[38] T. Lindgren, K. Deutsch, E. Schell et al., "Using mobile clinics to deliver HIV testing and other basic health services in rural Malawi," Rural and Remote Health Journal, vol. 11, no. 2, p. 1682, 2011.

[39] D. Romer, S. Sznitman, R. DiClemente et al., "Mass media as an HIV-prevention strategy: using culturally sensitive messages to reduce HIV-associated sexual behavior of at-risk African American youth," American Journal of Public Health, vol. 99, no. 12, pp. 2150-2159, 2009.

[40] E. Rogers, Diffusion of Innovations, Free Press, New York, NY, USA, 5th edition, 2003.

[41] J. Foreit and S. Raifman, Increasing Access to Family Planning (FP) and Reproductive Health (RH) Services Through TaskSharing between Community Health Workers (CHWs) and Community Mid-Level Professionals in Large-Scale Publicsector Programs: a Literature Review to Help Guide Case Studies, 2011.

[42] K. Viswanathan, P. Hansen, M. Rahman, L. Steinhardt, A. Edward, S. Arwal et al., "Can community health workers increase coverage of reproductive health services?" Journal of Epidemiology \& Community Health, vol. 66, no. 10, 2011.

[43] WHO, Task Shifting: Global Recommendations and Guidelines, World Health Organization, Geneva, Switzerland, 2008.

[44] R. Zachariah, N. Ford, M. Philips et al., "Task shifting in HIV/ AIDS: opportunities, challenges and proposed actions for subSaharan Africa," Transactions of the Royal Society of Tropical Medicine and Hygiene, vol. 103, no. 6, pp. 549-558, 2009.

[45] J. Sherwani, S. Palijo, S. Mirza, T. Ahmed, N. Ali, and R. Rosenfeld, "Speech vs. touch-tone: telephony interfaces for information access by low literate users," in Proceedings of the International Conference on Information and Communication Technologies and Development (ICTD '09), pp. 447-457, April 2009.

[46] L. A. Kamwendo, "Childbirth experiences in Malawi," Childbirth Across Cultures, vol. 5, pp. 235-244, 2009.

[47] A. C. Munthali and E. M. Zulu, "The timing and role of initiation rites in preparing young people for adolescence and responsible sexual and reproductive behaviour in Malawi," African Journal of Reproductive Health, vol. 11, no. 3, pp. 150167, 2007.

[48] T. Veinot, R. Harris, L. Bella, I. Rootman, and J. Krajnak, "HIV/AIDS information exchange in rural communities: preliminary findings from a three-province study," Canadian Journal of Information and Library Science, vol. 30, no. 34, pp. 271-290, 2006.
[49] Ministry of Health, Prevention of Mother To Child Transmission of HIV and Paediatric HIV Care Guidelines, Lilongwe, Malawi, 2008.

[50] S. Yeatman, "HIV is an enemy of childbearers': the construction of local epidemiology in rural Malawi," Culture, Health and Sexuality, vol. 13, no. 4, pp. 471-483, 2011.

[51] Ministry of Health, National Sexual and Reproductive Health and Rights (SRHR) Policy, Lilongwe, Malawi, 2009.

[52] F. Kasenga, P. Byass, M. Emmelin, and A. K. Hurtig, "The implications of policy changes on the uptake of a PMTCT programme in rural Malawi: first three years of experience," Global Health Action, vol. 2, p. 1883, 2009.

[53] J. Harries, D. Cooper, L. Myer, H. Bracken, V. Zweigenthal, and P. Orner, "Policy maker and health care provider perspectives on reproductive decision-making amongst HIV-infected individuals in South Africa," BMC Public Health, vol. 7, p. 282, 2007.

[54] P. Orner, D. Cooper, L. Myer, V. Zweigenthal, L. G. Bekker, and J. Moodley, "Clients' perspectives on HIV/AIDS care and treatment and reproductive health services in South Africa," AIDS Care, vol. 20, no. 10, pp. 1217-1223, 2008.

[55] P. Oosterhoff, N. T. Anh, N. T. Hanh, P. N. Yen, P. Wright, and A. Hardon, "Holding the line: Family responses to pregnancy and the desire for a child in the context of HIV in Vietnam," Culture, Health and Sexuality, vol. 10, no. 4, pp. 403-416, 2008.

[56] J. J. Myers, W. T. Steward, E. Charlebois, K. A. Koester, A. Maiorana, and S. F. Morin, "Written clinic procedures enhance delivery of HIV "prevention with positives" counseling in primary health care settings," Journal of Acquired Immune Deficiency Syndrome, vol. 37, pp. S95-S100, 2004.

[57] J. Fehringer, F. I. Bastos, E. Massard, L. Maia, J. H. Pilotto, and D. Kerrigan, "Supporting adherence to highly active antiretroviral therapy and protected sex among people living with HIV/AIDS: The role of patient-provider communication in Rio de Janeiro, Brazil," AIDS Patient Care and STDs, vol. 20, no. 9, pp. 637-648, 2006.

[58] C. K. Mbekenga, H. I. Lugina, K. Christensson, and P. Olsson, "Postpartum experiences of first-time fathers in a Tanzanian suburb: a qualitative interview study," Midwifery, vol. 27, no. 2, pp. 174-180, 2011.

[59] D. K. Mayer, N. C. Terrin, G. L. Kreps et al., "Cancer survivors information seeking behaviors: a comparison of survivors who do and do not seek information about cancer," Patient Education and Counseling, vol. 65, no. 3, pp. 342-350, 2007. 


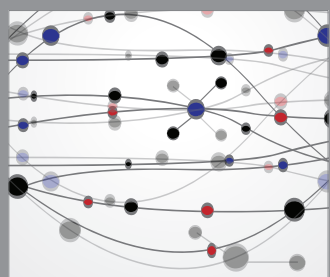

The Scientific World Journal
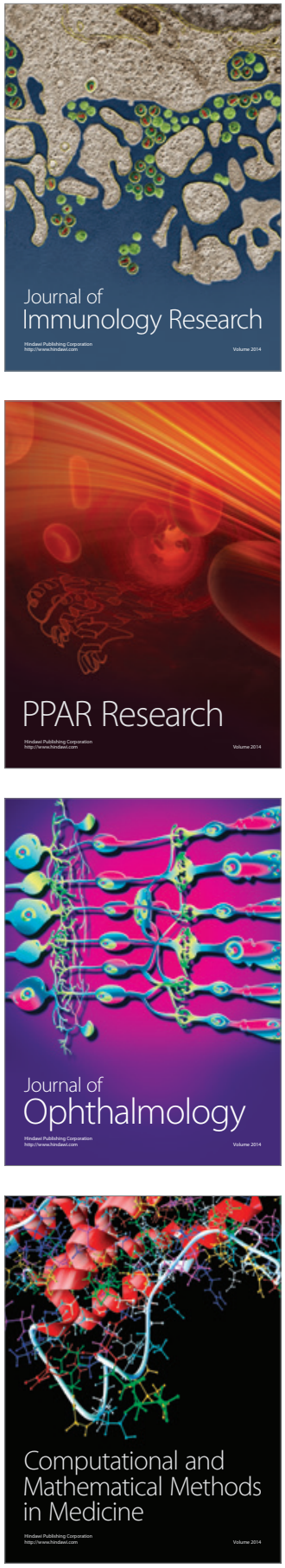

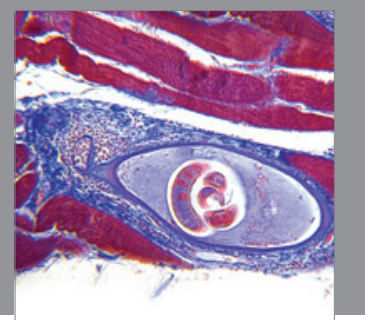

Gastroenterology

Research and Practice
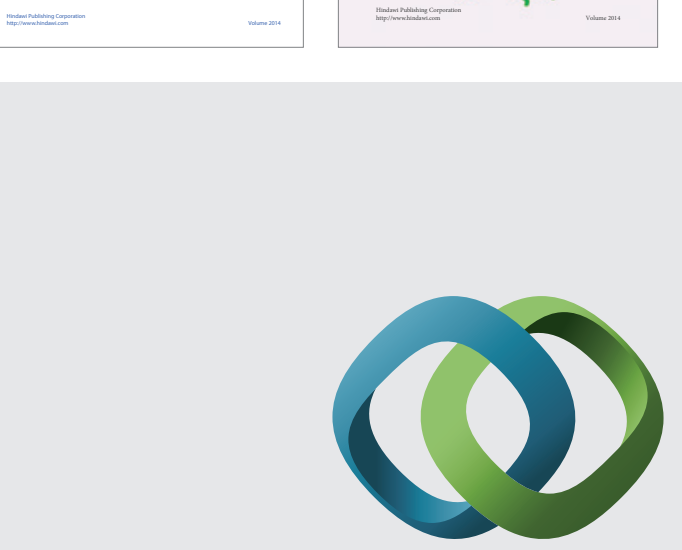

\section{Hindawi}

Submit your manuscripts at

http://www.hindawi.com
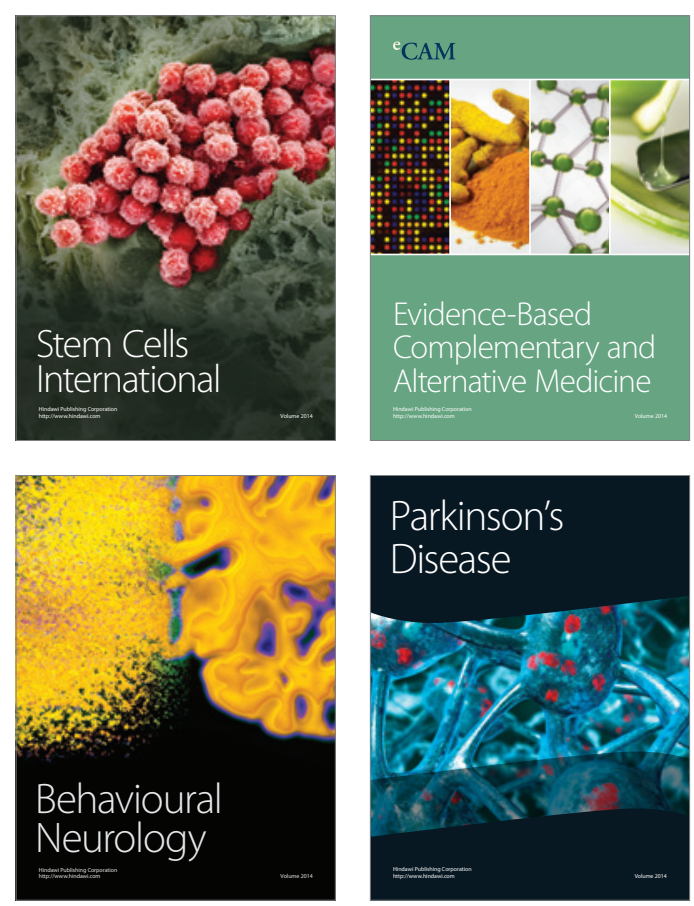

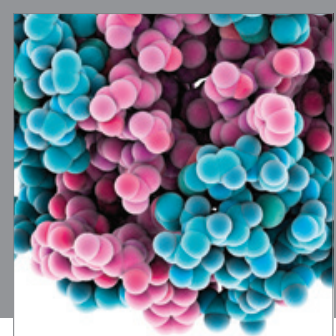

Journal of
Diabetes Research

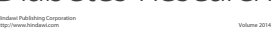

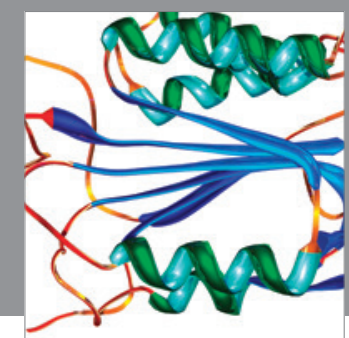

Disease Markers
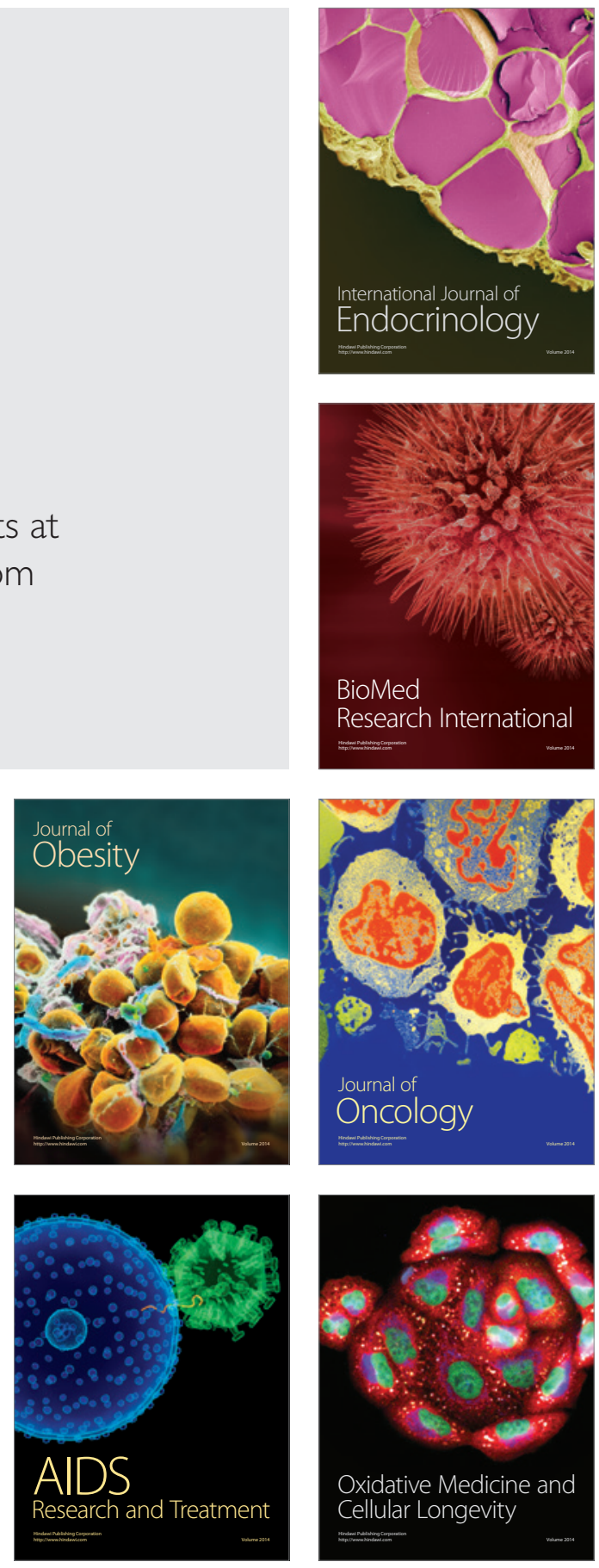